\title{
eCommons@AKU
}

Department of Paediatrics and Child Health

Division of Woman and Child Health

April 2017

\section{Progress in maternal and child health: how has South Asia fared?}

\author{
Nadia Akseer \\ Centre for Global Child Health, Hospital for Sick Children, Toronto, Canada \\ Mahdis Kamali \\ Centre for Global Child Health, Hospital for Sick Children, Toronto, Canada \\ Shams E. Arifeen \\ Maternal and Child Health Division, International Centre for Diarrhoeal Disease Research, Bangladesh \\ Ashar Muhammad Malik \\ Aga Khan University, ashar.malik@aku.edu \\ Zaid Ahmad Bhatti \\ Aga Khan University, zaid.bhatti@aku.edu \\ See next page for additional authors
}

Follow this and additional works at: https://ecommons.aku.edu/

pakistan_fhs_mc_women_childhealth_paediatr

Part of the Pediatrics Commons

\section{Recommended Citation}

Akseer, N., Kamali, M., Arifeen, S. E., Malik, A. M., Bhatti, Z. A., Thacker, N., Maksey, M., D’Silva, H., da Silva, I. C., Bhutta, Z. A. (2017). Progress in maternal and child health: how has South Asia fared?. BMJ, 357(j1608), 1-6.

Available at: https://ecommons.aku.edu/pakistan_fhs_mc_women_childhealth_paediatr/357 


\section{Authors}

Nadia Akseer, Mahdis Kamali, Shams E. Arifeen, Ashar Muhammad Malik, Zaid Ahmad Bhatti, Naveen Thacker, Mahesh Maksey, Harendra D’Silva, Inacio CM da Silva, and Zulfiqar Ahmed Bhutta 


\title{
Progress in maternal and child health: how has South Asia fared?
}

\author{
Although maternal and child health has improved over the past decade, much remains to be \\ done. Nadia Akseer and colleagues highlight the deficiencies and how to ensure progress
}

n our review of the state of maternal and child health in South Asia published in The BMJ 12 years ago, ${ }^{1}$ we highlighted rampant poverty, malnutrition, and lack of female empowerment as key barriers to change. Since then, the region has seen much focus on the millennium development goals related to maternal and child health as well as economic development. This article explores the progress and current state of reproductive, maternal, newborn and child health throughout South Asia, and presents a snapshot of the regions' preparedness for the sustainable development goals. ${ }^{2}$

\section{Methods and data sources}

Our analysis focuses on countries that are active members of the South Asian Association for Regional Cooperation: Afghanistan, Bangladesh, Bhutan, India, Maldives, Nepal, Pakistan, and Sri Lanka. We used national and global data sources sources to assess maternal mortality, ${ }^{3}$ child mortality, ${ }^{4}$ and stillbirths ${ }^{5}$ as well as causes of death. ${ }^{6-8}$

We calculated coverage rates for interventions and health indicators for mothers, infants, and children in South Asia from UN, World Bank, and WHO sources. ${ }^{8-13}$ Full definitions of the variables and details of the methods are provided in the appendix on bmj.com.

\section{Mortality trends and causes of death}

Globally, maternal mortality ratio dropped from 385 to 216 deaths per 100000 live births from, 1990 to 2015, a 44\% reduction. ${ }^{3}$ Never-

\section{KEY MESSAGES}

While South Asia has reduced maternal mortality ratio across the region, mortality remains high in many countries including Afghanistan, Pakistan, and Nepal

Despite progress in delivering antenatal care and vaccinations, wide disparities exist across wealth groups and between rural and urban populations in many countries Social determinants and health systems or policies are important contributors to observed improvement and differentials in the region

Ongoing challenges include conflict or insecurity, malnutrition, encouraging empowerment of girls and women, and supporting better and timely data collection theless, around 303000 mothers die every year, about $22 \%$ of whom are in South Asia, with India accounting for the bulk of these deaths. Maternal mortality fell substantially in all South Asian countries during this period (ranging from a 59\% reduction in Pakistan and Sri Lanka to $90 \%$ in the Maldives), with an overall reduction of $68 \%$ (fig 1). Afghanistan had the highest maternal mortality ratio in the region in 1990 (1340/100 000 births) and still had the highest ratio in 2015 despite a 70\% fall. The main causes of maternal death vary across South Asia (appendix), though maternal haemorrhage, hypertensive disorders, obstructed labour and uterine rupture, and abortion, miscarriage, or ectopic pregnancy are leading causes in many countries.

Mortality among children under 5 years reduced by about half from 1990 to 2015 (91 to 43 deaths per 1000 live births) across the world and by $60 \%$ in South Asia (from $129 / 1000$ to $53 / 1000) .^{4}$ Of the 5.9 million children under 5 who died in 2015, almost 1.9 million (31\%) were in South Asia. Pneumonia and diarrhoea related illness are the two leading preventable causes of child mortality in South Asia (appendix), leading to about half of all child deaths in most countries. Injuries are responsible for at least a further $10 \%$. In Sri Lanka and Maldives congenital anomalies cause a third of child deaths.

Over half (57\%) of deaths among children under 5 in South Asia occur in the first 28 days of life; this amounts to more than 1 million newborns dying every year in the region. ${ }^{4}$ Moreover, of the 2.6 million stillbirths that occur globally every year, about 37\% (almost 1 million) are in South Asia. ${ }^{5}$ Newborn mortality rates fell from 1990 to 2015; stillbirth rates also fell, although more slowly (appendix). Newborn mortality rates continue to be highest in Pakistan (45.5 deaths per 1000 live births) and Afghanistan (35.5). The main causes of newborn death are fairly consistent across the region, with preterm birth causing about one third of deaths and intrapartum related events; infections, including sepsis and meningitis; and congenital anomalies each contributing about one fifth of deaths (appendix). Some variation exists across countries. Robust data on causes of stillbirths were not available for comparison.

\section{Coverage of essential interventions}

We explored a range of evidence based essential interventions for mothers and children that are associated with improved child and maternal survival (see appendix for detailed list). Figure 2 shows the wide differences in coverage across the region. Contraceptive use is about $55 \%$ on average and is lowest in Afghanistan (31\%) and highest in Sri Lanka and Bhutan (about 70\%). About $70 \%$ of women have at least one antenatal visit in most countries, reaching almost $100 \%$ in Sri Lanka and Bhutan. Coverage drops for four or more antenatal care visits and skilled birth attendance; these interventions have the widest variation across countries, ranging from $23 \%$ in Afghanistan to 93\% in Sri Lanka. The provision of postnatal care within two days for both the newborn and mother is low in the region (30-40\% median) with some variation across countries. Data for Sri Lanka were not available.

Breastfeeding interventions (including early initiation and exclusive breastfeeding for 6 months) have about 50\% regional coverage, with a gap of $40 \%$ between the highest (Sri Lanka, Bhutan for early initiation;

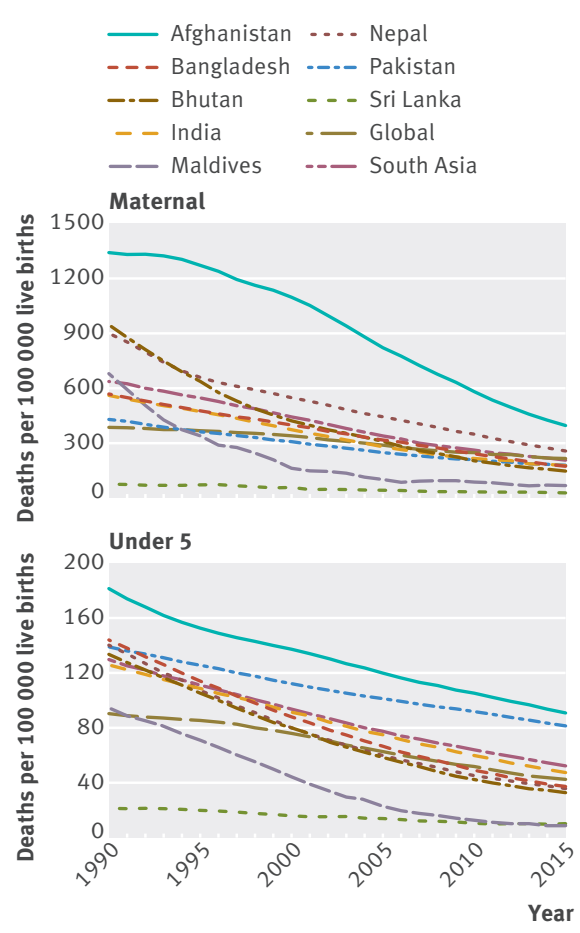

Fig 1 | Mortality trends in South Asian Countries, 1990-201534 


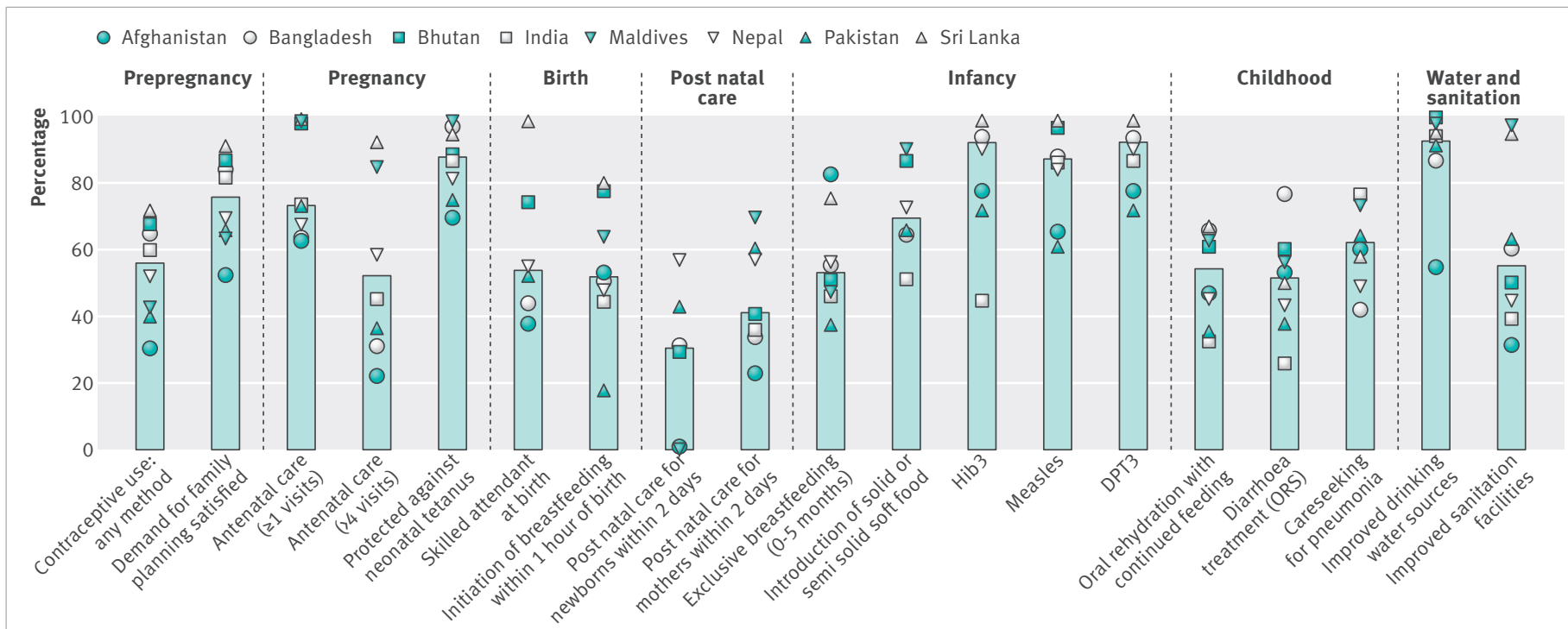

Fig 2 | Coverage of essential interventions in South Asian countries ${ }^{14}$

Afghanistan for exclusive breastfeeding) and lowest (Pakistan) countries. The region performs well in the provision of child vaccinations, with about $90 \%$ coverage on average for tetanus, Hib3, measles, and DPT3. Country coverage ranges from about $70 \%$ to $100 \%$, with Afghanistan and Pakistan amongst the lowest and Sri Lanka consistently the highest.

Access to treatment for children with diarrhoea and pneumonia is moderate in the region (50-60\%). Oral rehydration solutions (ORS) and ORS with continued feeding are least used in India and Pakistan, and coverage rates are highest in Bangladesh. Conversely, care seeking for pneumonia is highest in India and Maldives (almost 80\% coverage) and lowest in Bangladesh (41\%).

\section{Coverage inequalities within countries}

We analysed socioeconomic and residence inequalities for two key interventions (skilled birth attendance and measles vaccination) as they represent opposite ends of the continuum of care and diverse delivery strategies (fig 3). Coverage gaps for skilled birth attendance between the richest and poorest quintiles and between urban and rural residents are evident in most countries, with gaps of at least $70 \%$ in India, Nepal, and Bhutan. Sri Lanka and Maldives have minimal to no gaps. Inequalities in measles vaccination were greatest for Pakistan, India, and Afghanistan, with lowest coverage rates among the poorest populations and those living in rural areas.

\section{Access to improved water and sanitation}

Equitable and sustainable access to safe water and improved sanitation and hygiene can improve outcomes in many ways through its implications for environmental cleanliness, health, reduced poverty, and equity. ${ }^{15}$ About $8 \%$ of maternal deaths worldwide are attributable to infections that can be directly linked to unhygienic conditions during labour and to poor hygiene practices in the six weeks after birth. ${ }^{1617}$ The availability of improved water is almost universal throughout the region except in Afghanistan, where only $55 \%$ of the population has access (see appendix on bmj.com). ${ }^{18}$ Improved sanitation facilities are less available in the region (about 55\% regional
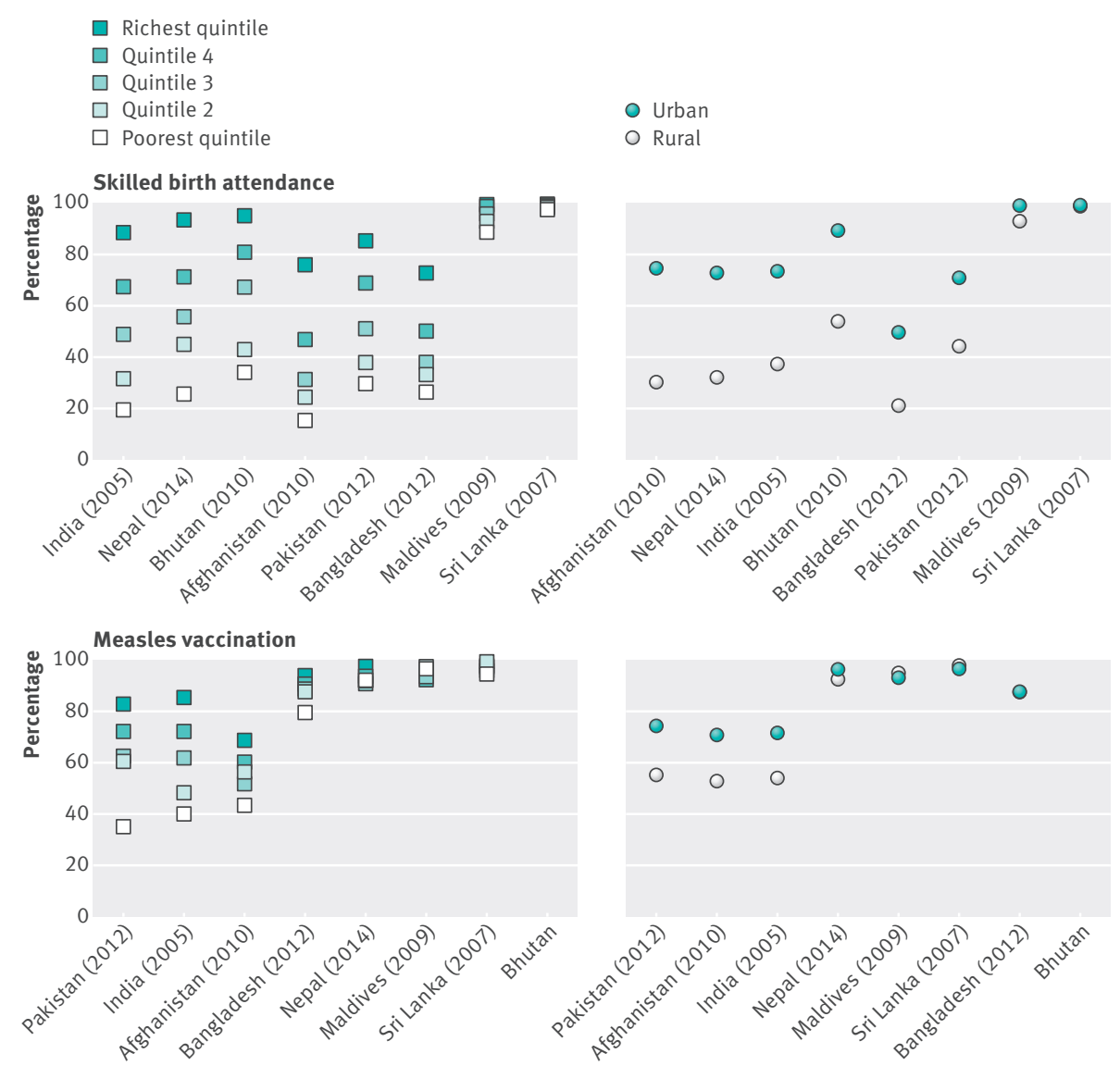

Fig 3 | Inequalities in skilled birth attendance and measles vaccination by country ${ }^{14}$ 

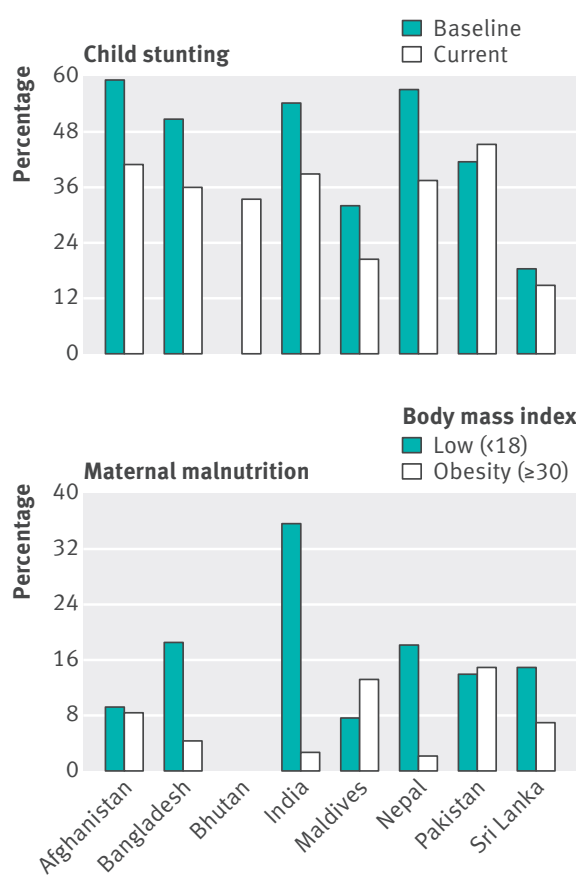

Fig 4 | Malnutrition trends in South Asian countries using latest available data. Baseline figures for stunting relate to earliest available estimate between 1999 and $2004^{19}$

(from $42 \%$ to $45 \%$ ). Despite progress, current levels of stunting are more than $30 \%$ in most countries in the region, except Sri Lanka $(15 \%)$ and Maldives (20\%). Currently around a third of children are underweight in most countries except Bhutan (13\%) and Maldives (18\%) (appendix). Prevalence of wasting has hardly changed over the decade, and currently ranges from $6 \%$ in Bhutan to $21 \%$ in Sri Lanka.

Both overnutrition and undernutrition are concerns among women age 15-49 years in
South Asia (fig 4). Maternal underweight (defined as body mass index $<18.5$ ) is prevalent in about $36 \%$ of women in India-about double that in the next highest countries (Nepal 18\% and Bangladesh 19\%). Obesity (BMI $\geq 30)$ is highest in Pakistan (15\%) and Maldives (13\%).

\section{Empowerment of girls and women}

Empowered girls and women are more inclined to seek healthcare when in need and consequently have improved health outcomes and survival. Empowered females are more educated, delay marriage, postpone childbearing, and have fewer and spaced pregnancies, all of which are known to improve maternal and child health. ${ }^{20}$

All countries in the region have experienced an overall reduction in fertility rates since 2004, ranging between $9 \%$ and $36 \%$ (table 1). Current fertility rates are highest in Afghanistan and Pakistan. Births among adolescent girls (age 15-19 years) have declined more than 50\% in Bhutan, Maldives, and India. Pakistan has made the least progress in reducing fertility among adolescent girls ( $11 \%$ reduction). Average age at first marriage is lowest in Bangladesh (19.2 years), and highest in Sri Lanka (23.6 years). Although most countries have increased the average age of marriage by $2 \%-7 \%$, Afghanistan had the fastest rate of change over the past decade (from 15.0 years in 2006 to 21.2 years in 2011).

Literacy of women (age $\geq 15$ years) is greater than 90\% in Sri Lanka (92\%) and the Maldives (99\%), and about half in other South Asian nations except Afghanistan where only $24 \%$ of women are literate. Liter- acy of young women (age 15-24 years) is $>85 \%$ in all countries except Pakistan (67\%) and Afghanistan (46\%).

\section{Investments in health systems}

The density of healthcare staff, including physicians, nurses, and midwives, varies widely across the region. South Asia has seen various health system and outreach innovations targeted at marginalised populations with poor access to health services. These have included deployment of community health workers through non-governmental health workers in Bangladesh ${ }^{21}$ to public sector workers such as lady health workers in Pakistan ${ }^{22}$ or accredited social health activists (ASHA) in India. ${ }^{23}$

There have also been large scale experiments with community engagement through women's groups ${ }^{24}$ as well and financial incentive programmes, both conditional on recipients' health behaviour, such as India's Janani Suraksha Yojana programme supporting facility births, ${ }^{25}$ and unconditional, such as the income support programme in Pakistan targeting women. ${ }^{26}$

Table 2 lists the key health initiatives implemented in South Asia during the period of the millennium development goals. Common features of such programmes include adaptation of a basic package of healthcare services and strategies to expand universally, contracting out delivery of healthcare services to non-governmental organisations to enable rapid scale-up, financial incentive programmes or abolishing user fees, and community based health care initiatives and training of midwives.

High out-of-pocket health expenditures annually drag about $4 \%$ of the population

\begin{tabular}{|c|c|c|c|c|c|c|c|c|}
\hline Country & Afghanistan & Bangladesh & Bhutan & India & Maldives & Nepal & Pakistan & Sri Lanka \\
\hline \multicolumn{9}{|c|}{ Fertility rate (average births per woman): } \\
\hline 2014 & 4.8 & 2.2 & 2.0 & 2.4 & 2.1 & 2.2 & 3.6 & 2.1 \\
\hline 2004 & 7.0 & 2.8 & 3.0 & 3.0 & 2.4 & 3.4 & 4.1 & 2.3 \\
\hline$\%$ change & -30.7 & -21.7 & -31.6 & -20.1 & -12.2 & -35.2 & -12.4 & -8.6 \\
\hline \multicolumn{9}{|c|}{$\begin{array}{l}\text { Adolescent fertility rate (average births per } 1000 \text { women } \\
\text { aged 15-19): }\end{array}$} \\
\hline 2014 & 76.7 & 83.5 & 22.7 & 25.7 & 7.3 & 72.5 & 39.2 & 15.4 \\
\hline 2004 & 134.7 & 101.1 & 61.7 & 54.0 & 20.1 & 104.1 & 44.2 & 25.7 \\
\hline$\%$ change & -43.0 & -17.5 & -63.2 & -52.4 & -63.7 & -30.4 & -11.4 & -40.1 \\
\hline \multicolumn{9}{|l|}{ Mean age at first marriage: } \\
\hline Current (year of data) & $21.2(2011)$ & $19.2(2013)$ & $21.4(2010)$ & 20.7 (2011) & $22.4(2009)$ & 20.7 (2014) & 23.1 (2013) & $23.6(2007)$ \\
\hline Baseline (year of data) & $15.0(2006)$ & $18.7(2004)$ & $21.8(2005)$ & $20.2(2006)$ & $22.9(2006)$ & $19.4(2006)$ & $22.3(2003)$ & NA \\
\hline$\%$ change & 41.3 & 2.7 & -1.8 & 2.5 & -2.2 & 6.7 & 3.6 & - \\
\hline \multicolumn{9}{|c|}{ Female adult literacy rate (\% aged $\geq 15$ ): } \\
\hline 2015 & 23.9 & 58.3 & 55.1 & 63.0 & 98.9 & 54.8 & 42.7 & 91.7 \\
\hline Baseline (year of data) & NA & NA & $38.7(2005)$ & $50.8(2006)$ & 98.4 (2006) & NA & 35.4 (2005) & $89.1(2006)$ \\
\hline$\%$ change & - & - & 42.4 & 23.9 & 0.5 & -- & 20.7 & 2.9 \\
\hline \multicolumn{9}{|c|}{ Literacy rate of young women (\% aged 15-24): } \\
\hline 2015 & 46.1 & 85.9 & 90.4 & 87.3 & 99.5 & 87.4 & 66.8 & 99.2 \\
\hline Baseline (year of data) & NA & NA & $68.0(2005)$ & $74.4(2006)$ & $99.4(2006)$ & NA & $53.1(2005)$ & $97.9(2006)$ \\
\hline$\%$ change & - & - & 33.0 & 17.3 & 0.1 & - & 25.8 & 1.3 \\
\hline
\end{tabular}




\begin{tabular}{|c|c|c|c|}
\hline Country & Reform & Year started & Focus \\
\hline \multirow[t]{3}{*}{ Afghanistan } & Midwifery training programme & 2002 & Provided pre-services training to midwife for community care and hospital based care \\
\hline & Basic package of health services & 2004 & Basic primary care services including maternal health and family planning \\
\hline & Contracting of primary health services to NGO & 2004 & $\begin{array}{l}\text { Capitation based ( } \$ 3.8 \text { to } \$ 5.1 \text { per capita) contracts with providers through a bidding } \\
\text { process }\end{array}$ \\
\hline \multirow[t]{4}{*}{ Bangladesh } & BRAC Shasthya Shebikas community health workers & $1970^{\star}$ & Scaled up to all 64 districts: from 1080 community health workers to 91000 by 2010 \\
\hline & SWAp & $1998^{*}$ & $\begin{array}{l}\text { A shift from project based planning to sector-wide planning, management, and } \\
\text { financing. }\end{array}$ \\
\hline & Bangladesh national strategy for maternal health & 2001 & $\begin{array}{l}\text { Adopted community based skilled birth attendant to supplement institution based } \\
\text { care }\end{array}$ \\
\hline & Demand side financing & 2007 & Maternal health voucher scheme. Current converge in 53 upazilas \\
\hline \multirow[t]{2}{*}{ Bhutan } & Universal access to health services & 2008 & $\begin{array}{l}\text { In the constitution of } 2008 \text { health is recognised as human right and as one of the nine } \\
\text { domains of gross national happiness. }\end{array}$ \\
\hline & Health policy & 2012 & $\begin{array}{l}\text { Pledges universal health access to modern and traditional care, } 90 \% \text { population living } \\
\text { within three hours walking distance to a health facility }\end{array}$ \\
\hline \multirow[t]{4}{*}{ India } & National rural health mission & 2004 & $\begin{array}{l}\text { Integration of vertical reproductive and maternal health programmes and health } \\
\text { system strengthening in } 18 \text { states }\end{array}$ \\
\hline & Janani Suraksha Yojana & 2005 & Conditional cash transfer to pregnant women \\
\hline & Accredited Social Health Activist (ASHA) & 2006 & 820000 community health workers (ASHA) as of 2012 \\
\hline & Rashtriya SwasthyaBima Yojna & 2008 & Inpatient (including maternity) coverage for the poor. 41.3 million people covered by 2016 \\
\hline \multirow[t]{2}{*}{ Maldives } & Madhana & 2008 & $\begin{array}{l}\text { Publicly funded health insurance scheme initially covering public employees and } \\
\text { elderly people }\end{array}$ \\
\hline & Aasandha & 2012 & $\begin{array}{l}\text { Universal health coverage (up to Rf } 100 \text { 000) including treatment in neighbouring } \\
\text { countries }\end{array}$ \\
\hline \multirow[t]{4}{*}{ Nepal } & National safe motherhood plan & 2002 & $\begin{array}{l}\text { Increase the access of poor and marginalised people on the reproductive health } \\
\text { services }\end{array}$ \\
\hline & Free healthcare policy & 2006 & $\begin{array}{l}\text { Abolishing user fee at public facilities. By } 2009 \text { free essential health services } \\
\text { including maternity services }\end{array}$ \\
\hline & National safe motherhood/ neonatal health plan & 2006 & Birth preparedness package \\
\hline & Community based neonatal care package & 2007 & Piloted in 10 districts and planned to expand to 35 more districts by 2013 \\
\hline \multirow[t]{6}{*}{ Pakistan } & Social Action Program I \& II & 1992/1998 & Sector wide approach for primary and secondary healthcare \\
\hline & $\begin{array}{l}\text { National programme for family planning and } \\
\text { primary healthcare }\end{array}$ & 1994 & $\begin{array}{l}\text { Currently over } 100000 \text { lady health workers covering more than } 80 \% \text { of rural } \\
\text { population }\end{array}$ \\
\hline & People's primary healthcare initiative & 2004 & $\begin{array}{l}\text { Contracting of primary healthcare facilitates to NGOs. Implemented in } 75 \text { districts } \\
\text { (out of 113) }\end{array}$ \\
\hline & Community midwife programmr & 2005 & New cadre of community midwife is introduced \\
\hline & $18^{\text {th }}$ constitutional amendment & 2010 & Devolution of health sector to the provinces \\
\hline & National health insurance scheme & 2014 & $\begin{array}{l}\text { Financial protection from health shocks to the population living below poverty line for } \\
\text { inpatient care including maternity services. }\end{array}$ \\
\hline \multirow[t]{3}{*}{ Sri Lanka } & National maternal and child healthcare program & $1965^{\star}$ & Family planning and reproductive health were integrated \\
\hline & $\begin{array}{l}\text { Strategic framework for health development } \\
\text { 2004-2015 }\end{array}$ & 2003 & Health master plans and health development plan were implemented \\
\hline & National health development plan & 2012 & $\begin{array}{l}\text { World Bank assisted project for outsourcing non-clinical services and other financing } \\
\text { reforms }\end{array}$ \\
\hline
\end{tabular}

into poverty in the three most populous countries of the region: India, Bangladesh, and Pakistan (table 3). Only four countries had data available for spending on maternal and child health. The proportion of total health expenditure was 9.8\% in Sri-Lanka, $12 \%$ in Bangladesh, $16 \%$ in Afghanistan, and $21 \%$ in Pakistan.

\section{Discussion}

Despite wide variations, South Asia has made impressive progress in maternal and child health over the past decade. In many countries with widespread conflict and grinding poverty, notably Nepal and Afghanistan, these gains are remarkable. Although countries have used different approaches to achieve these reductions, many have involved community based programmes to manage demand and deliver services.

Nepal invested heavily in community based approaches to increase detection of serious childhood illnesses and management of pneumonia. ${ }^{37}$ A range of innovative approaches for addressing maternal health and nutrition through women's groups provided some of the first evidence on the role of community empowerment in rural Makwanpur, Nepal. ${ }^{38}$ Bangladesh also used interventions including community empowerment, investments in education and young women, and national roll-out of community health workers through non-governmental organisations such as BRAC. It was able to rapidly roll-out interventions through a range of community outreach programmes. ${ }^{3940}$ However, the reductions in maternal mortality in Bangladesh far outstripped the gains in skilled birth attendance coverage and facility births. ${ }^{41}$ The innovative deployment of public sector community health workers in Pakistan, ${ }^{42}$ as well as India, ${ }^{43}$ suggest that such strategies could be deployed at scale.
Similarly, reductions in child mortality (and especially from diarrhoeal diseases) have been notable, but while there have been major gains in use of oral rehydration therapy, care seeking for childhood pneumonia is low and rates of childhood undernutrition are still high. ${ }^{44}$ Investments in social determinants and non-health sectors such as education, especially girls' education and female empowerment to reduce early marriages and high fertility rates, as well as effective communication strategies are likely to be especially important to improve and sustain gains in maternal and child health.

In war ravaged Afghanistan, because of the shortage of skilled public sector workers, the government adopted contracted non-governmental organisations to provide a basic package of primary care services. ${ }^{45}$ Although the transaction costs were relatively high, there were limited 


\begin{tabular}{|c|c|c|c|c|c|c|c|c|}
\hline & India & Bangladesh & Pakistan & Afghanistan & Sri-Lanka & Nepal & Bhutan & Maldives \\
\hline Health expenditure as \% of GDP & 4.0 & 3.5 & 3.0 & 8.0 & 3.2 & 5.3 & 3.7 & 9.2 \\
\hline Per capita health expenditure (\$) & 59 & 27 & 40 & 56 & 97 & 25 & 107 & 561 \\
\hline Government health expenditure as \% total health expenditure (\%) & 28.6 & 23.0 & 32.1 & 5.6 & 55.0 & 21.0 & 71.0 & 44.0 \\
\hline Out-of-pocket payments as \% total health expenditure & 64.2 & 63.0 & 60.4 & 73.3 & 37.9 & 54.8 & 11.0 & 49.0 \\
\hline Child and maternal health as \% total health expenditure & - & 12.0 & 21.0 & 16.0 & 9.8 & - & - & - \\
\hline \% from official development assistance & 0.3 & 8.3 & 7.0 & 20.8 & 1.5 & 18.9 & 18.0 & 3.0 \\
\hline$\%$ of population impoverished because of out-of-pocket health payments & 3.7 & 3.8 & 3.8 & - & 0.3 & 3.0 & - & - \\
\hline$\%$ of population with out-of-pocket health expenditure $>25 \%$ of total expenditure & 1.8 & 4.5 & 5.0 & - & 0.5 & 1.2 & - & - \\
\hline
\end{tabular}

Source: National health accounts for India (2013-14), Bangladesh (2012), Pakistan (2013-14), Sri Lanka (2013), Afghanistan (2011-12), Maldives (2011), Nepal (2008-09), Bhutan (2009-10). Dooslear et al (2006) for Impoverishment impact of OOP health payments (except Pakistan Malik, 2016) and Doorslaer (2007) for 0OP health payments exceeding 25\% of the household total expenditure

alternatives and the model allowed for rapid population coverage in difficult to reach rural populations.

High rates of newborn mortality and intrapartum stillbirths are a major challenge across the region, and are associated with poor quality of care in both community and facility settings. ${ }^{46}$ Further reductions in under 5 mortality will require action on the dual challenge of improving care during pregnancy and childbirth in community settings and facilitation of facility births, as well as improving care of newborns in referral facilities. Pakistan invested in a major national programme of primary care using "lady health workers," who now number over 100000 and cover almost two thirds of the rural population, ${ }^{47}$ and India has also introduced a major public sector programme of community based health workers. Evidence shows that there is considerable opportunity for innovations in facilitating the work of frontline workers to improve mother and child health. ${ }^{22} 434849$ In other regions of South Asia where there have been relatively rapid gains, we need to invest in strategies to improve the quality of care in referral facilities, especially those responsible for secondary care.

Major challenges remain. The rapid growth of urban slums-often home to over a third of the population of megacitiesposes huge challenges to effective care and governance. These and other marginalised populations, including indigenous groups and those relegated on the basis of ethnicity, religion, or caste systems, will require innovative targeting to reduce inequities. Furthermore, reaching the poorest and remote populations in countries where care is focused on rich and urban populations such as Afghanistan and Pakistan, is critical. Recent reviews have highlighted innovative strategies for reducing such inequities to improve maternal and child health. ${ }^{50}$

Finally, the state and international partners must support and protect women and children who are at risk of gender based violence, lack of economic security, and physical immobility. High rates of maternal and adolescent malnutrition remain tenacious underlying risk factors for ill health and mortality in the region. Direct policies and initiatives to improve nutrition of all populations are critical for health gains in South Asia. Low rates of breastfeeding and complementary feeding are a concern and should be prioritised for large scale intervention. Quality and timely data are vital for effective monitoring, evaluation, and rapid feedback. Countries should focus on efforts to enhance administrative databases, health management information systems, birth and death registries, and national surveys on health and wellbeing to track progress towards the sustainable development goals.

South Asia comprises a substantial chunk of the global population and contains some of the highest maternal and child mortality rates worldwide. Gains over the past decade provide evidence that progress is possible, but much more can be done with focus on scaling up evidence based interventions and addressing barriers as key investments in reaching the sustainable development goals. Contributors and sources: This consortium of authors have diverse subject expertise related to maternal, newborn and child health among countries in the region. Drs Bhutta, Arifeen and Nadia Akseer have undertaken Countdown country case studies in the region. The review was conceived in a planning meeting for the special South Asia collection in Dubai in January 2016.

Competing interests: We have read and understood BMJ policy on declaration of interests and have no relevant interests to declare.

Provenance and peer review: Commissioned; externally peer reviewed.

Nadia Akseer, biostatistician ${ }^{1,2}$

Mahdis Kamali, research assistant ${ }^{1}$

Shams E Arifeen, senior scientist ${ }^{3}$

Ashar Malik, senior instructor ${ }^{4}$

Zaid Bhatti, statistician ${ }^{4}$

Naveen Thacker, consultant paediatrician 5

Mahesh Maksey, head of foundation ${ }^{6}$

Harendra D’Silva, professor ${ }^{7}$

Inacio CM da Silva, epidemiologist ${ }^{\S}$

Zulfiqar A Bhutta, professor $r^{1,2,4}$

${ }^{1}$ Centre for Global Child Health, Hospital for Sick

Children, Toronto, Canada
2Dalla Lana School of Public Health, University of Toronto, Toronto, Canada

${ }^{3}$ Maternal and Child Health Division, International Centre for Diarrhoeal Disease Research, Bangladesh (icddr,b)

${ }^{4}$ Centre of Excellence in Women and Child Health, Aga Khan University, Karachi, Pakistan

${ }^{5}$ Deep Children Hospital and Research Centre, Gandhidham, Gujrat, India

${ }^{6}$ Nepal Public Health Foundation, Kathmandu, Nepal 7Faculty of Medicine, University of Colombo, Sri Lanka \&International Center for Equity in Health, Federal University of Pelotas, Brazil

Correspondence to: Z A Bhutta zulfiqar.bhutta@ sickkids.ca

Bhutta ZA, Gupta I, de'Silva H, et al. Maternal and child health: is South Asia ready for change?BMJ 2004:328:816-9. doi:10.1136/bmj.328.7443.816.

2 United Nations. Transforming our world: the 2030 agenda for sustainable development. UN, 2015 United Nations. Maternal mortality estimate interagency group (UN-MMEIG). UN, 2016. http://www. who.int/reproductivehealth/publications/monitoring/ maternal-mortality-2015/en/

4 United Nations. Interagency for child mortality estimation (UN-IGME). UN, 2016. http://www.unicef. org/publications/files/Child_Mortality_Report_2015 Web_9_Sept_15.pdf.

Lawn JE, Blencowe H, Waiswa P, et al. Lancet Ending Preventable Stillbirths Series Study Group Lancet Stillbirth Epidemiology Investigator Group. Stillbirths: rates, risk factors, and acceleration towards 2030. Lancet 2016;387:587-603. doi:10.1016/ S0140-6736(15)00837-5.

6 Kassebaum NJB-VA, Bertozzi-Villa A, Coggeshall MS, et al. Global, regional, and national levels and causes of maternal mortality during 1990-2013: a systematic analysis for the Global Burden of Disease Study 2013. Lancet 2014;384:980-1004. doi:10.1016/ S0140-6736(14)60696-6.

7 Liu L, Oza S, Hogan D, et al. Global, regional, and national causes of under-5 mortality in 2000-15: an updated systematic analysis with implications for the Sustainable Development Goals. Lancet 2016;388:3027-35.

8 UNFPA. State of the world population 2016. 2016. http://www.unfpa.org/sites/default/files/sowp/ downloads/The_State_of_World_Population_2016_English.pdf.

9 United Nations Populations Division. 2016. https:// esa.un.org/unpd/wpp/.

10 Unicef. Global database. 2016. http://data.unicef.org/.

11 Unicef. Infant and young child feeding report 2016. http://www.unicef.org/nutrition/files/Final_IYCF programming guide_2011.pdf.

12 WHO/Unicef. Coverage estimates for immunization. 2016 http://www.who.int/immunization/monitoring_ surveillance/data/en/.

13 WHO/Unicef. Joint monitoring programme (JMP) for water supply and sanitation. 2016. www.wssinfo.org/ data-estimates/.

14 Countdown to. 2015. A decade of tracking progress for maternal, newborn and child survival: the 2015 report. http://countdown2030.org/ reports-and-articles/2015-final-report 
15 Waddington $\mathrm{H}$, Snilstveit B. Effectiveness and sustainability of water, sanitation, and hygiene interventions in combating diarrhoea. I Dev Effect 2009;1:295-335doi:10.1080/19439340903141175.

16 Goodburn E, Campbell O. Reducing maternal mortality in the developing world: sector-wide approaches may be the key. BMJ 2001;322:917-20. doi:10.1136/ bmj.322.7291.917.

17 Gravett CA, Gravett MG, Martin ET, et al. Serious and life-threatening pregnancy-related infections: opportunities to reduce the global burden. PLoS Med 2012;9:e1001324. doi:10.1371/journal.pmed.1001324.

18 Bhutta Z, Nundy S. On the brink of conflict: the people of South Asia deserve better. BMJ 2017;357:j1528.

19 Unicef, WHO, World Bank. Joint malnutrition estimates. 2015http://www.who.int/nutgrowthdb/estimates/en/.

20 Karlsen S, Say L, Souza I-P, et al. The relationship between maternal education and mortality among women giving birth in health care institutions: analysis of the cross sectional WHO global survey on maternal and perinatal health. BMC Public Health 2011;11:606. doi:10.1186/1471-2458-11-606.

21 Rahman M, Yunus FM, Shah R, et al. A controlled before-and-after perspective on the improving maternal, neonatal, and child survival program in rural Bangladesh: an impact analysis. PLoS One 2016:11:e0161647. doi:10.1371/journal pone.0161647.

22 Bhutta ZA, Soofi S, Cousens S, et al. Improvement of perinatal and newborn care in rural Pakistan through community-based strategies: a cluster-randomised effectiveness trial. Lancet 2011;377:403-12. doi:10.1016/S0140-6736(10)62274-X

23 Saprii L, Richards E, Kokho P, Theobald S. Community health workers in rural India: analysing the opportunities and challenges Accredited Social Health Activists (ASHAs) face in realising their multiple roles. Hum Resour Health 2015;13:95. doi:10.1186/ s12960-015-0094-3.

24 Prost A, Colbourn T, Seward N, et al. Women's groups practising participatory learning and action to improve maternal and newborn health in low-resource settings: a systematic review and meta-analysis. Lancet 2013;381:1736-46. doi:10.1016/ S0140-6736(13)60685-6.

25 Powell-Jackson T, Mazumdar S, Mills A. Financial incentives in health: New evidence from India's Janani Suraksha Yojana. J Health Econ 2015;43:154-69. doi:10.1016/j.jhealeco.2015.07.001.

26 Cheema I, Farhat M, Hunt S, Javeed S, Pellerano L, O’Leary S. Benazir income support programme. 2014.

27 Government of India, Ministry of Health and Family Welfare. National Health accounts estimates for India 2013-14. 2016 http://www.mohfw.nic.in/showfile. php?lid=4016

28 Government of the People's Republic of Bangladesh Ministry of Health and Family Welfare. Bangladesh national health accounts 1997-2012. 2015. http:// www.heu.gov.bd/pdf/bnha\%201997-2012.pdf.
29 Government of Pakistan, Pakistan Bureau of Statistics Pakistan national health accounts 2013-14. 2016 http://www.pbs.gov.pk/sites/default/files//NHA\%20 report\%202013-14..pdf

30 Ministry of Health, Nutrition \& Indigenous Medicine. Sri Lanka national health accounts, 2013. 2016 http:// www.health.gov.lk/moh_final/english/public/elfinder/ files/publications/NHA/Sri\%20Lanka\%20 National\%20Health\%20Accounts\%202013.pdf.

31 Islamic Republic of Afghanistan, Ministry of Public Health. Afghanistan national health accounts with subaccounts for reproductive health 2011-2012. 2013 http://www.healthpolicyproject.com/pubs/262 AfghanistanNHAReportFINAL.pdf.

32 Ministry of Health Maldives, World Health Organization. Maldives national health accounts 20112014 http:// www.searo.who.int/maldives/hsd-mav-1.pdf.

33 Government of Nepal, Ministry of Health and Population. National health accounts 2006/072008/09 2012 http://apps.who.int/nha/country/npl/ nepalnha.pdf.

34 Royal Government of Bhutan, Ministry of Health. National health accounts 2009-2010 2011 http:// apps.who.int/nha/country/btn/btn-nha report_2009-2010.pdf?ua=1.

35 van Doorslaer E, O'Donnell O, Rannan-Eliya RP, et al. Effect of payments for health care on poverty estimates in 11 countries in Asia: an analysis of household survey data. Lancet 2006;368:1357-64. doi:10.1016/ S0140-6736(06)69560-3.

36 van Doorslaer E, O'Donnell O, Rannan-Eliya RP, et al. Catastrophic payments for health care in Asia. Health Econ 2007;16:1159-84. doi:10.1002/hec.1209.

37 Dawson P, Pradhan Y, Houston R, Karki S, Poudel D, Hodgins S. From research to national expansion: 20 years' experience of community-based management of childhood pneumonia in Nepal. Bull World Health Organ 2008;86:339-43. doi:10.2471/BLT.07.047688.

38 Manandhar DS, Osrin D, Shrestha BP, et al. Members of the MIRA Makwanpur trial team. Effect of a participatory intervention with women's groups on birth outcomes in Nepal: cluster-randomised controlled trial. Lancet 2004;364:970-9. doi:10.1016/ S0140-6736(04)17021-9.

39 Chowdhury AMR, Bhuiya A, Chowdhury ME, Rasheed S, Hussain Z, Chen LC. The Bangladesh paradox: exceptional health achievement despite economic poverty. Lancet 2013;382:1734-45. doi:10.1016/ S0140-6736(13)62148-0.

40 El Arifeen S, Christou A, Reichenbach L, et al. Community-based approaches and partnerships: innovations in health-service delivery in Bangladesh. Lancet 2013;382:2012-26. doi:10.1016/ S0140-6736(13)62149-2.

41 El Arifeen S, Hill K, Ahsan KZ, Jamil K, Nahar Q Streatfield PK. Maternal mortality in Bangladesh: a Countdown to 2015 country case study. Lancet 2014;384:1366-74. doi:10.1016/ S0140-6736(14)60955-7.
42 Soofi S, Ahmed S, Fox MP, et al. Effectiveness of community case management of severe pneumonia with oral amoxicillin in children aged 2-59 months in Matiari district, rural Pakistan: a cluster-randomised controlled trial. Lancet 2012;379:729-37. doi:10.1016/ S0140-6736(11)61714-5.

43 Bhandari N, Mazumder S, Taneja S, Sommerfelt H, Strand TA. IMNCI Evaluation Study Group. Effect of implementation of Integrated Management of Neonatal and Childhood Illness (IMNCI) programme on neonatal and infant mortality: cluster randomised controlled trial. BMJ 2012;344:e1634. doi:10.1136/ bmj.e1634.

44 Rahman AE, Moinuddin M, Molla M, et al. Persistent Diarrhoea Research Group. Childhood diarrhoeal deaths in seven low- and middle-income countries. Bull World Health Organ 2014;92:664-71. doi:10.2471/ BLT.13.134809.

45 Akseer N, Salehi AS, Hossain SMM, et al. Achieving maternal and child health gains in Afghanistan: a Countdown to 2015 country case study. Lancet Glob Health 2016;4:e395-413. doi:10.1016/

S2214-109X(16)30002-X

46 Das JK, Rizvi A, Bhatti Z, et al. State of neonatal health care in eight countries of the SAARC region, South Asia: how can we make a difference?Paediatr Int Child Health 2015:35:174-86. doi:10.1179/20469055 $15 Y .0000000046$

47 Hafeez A, Mohamud BK, Shiekh MR, Shah SA, Jooma R. Lady health workers programme in Pakistan: challenges, achievements and the way forward. J Pak Med Assoc 2011:61:210-5.

48 Baqui AH, Saha SK, Ahmed ASMNU, et al. Projahnmo Study Group in Bangladesh. Safety and efficacy of alternative antibiotic regimens compared with 7 day injectable procaine benzylpenicillin and gentamicin for outpatient treatment of neonates and young infants with clinical signs of severe infection when referral is not possible: a randomised, open-label, equivalence trial. Lancet Glob Health 2015;3:e279-87. doi:10.1016 S2214-109X(14)70347-X.

49 Soofi S, Cousens S, Imdad A, Bhutto N, Ali N, Bhutta ZA. Topical application of chlorhexidine to neonatal umbilical cords for prevention of omphalitis and neonatal mortality in a rural district of Pakistan: a community-based, cluster-randomised trial. Lancet 2012;379:1029-36. doi:10.1016/ S0140-6736(11)61877-1.

50 Yuan B, Målqvist M, Trygg N, Qian X, Ng N, Thomsen S. What interventions are effective on reducing inequalities in maternal and child health in low- and middle-income settings? A systematic review. BMC Public Health 2014:14:634. doi:10.1186/1471-2458-14-634.

Cite this as: BMJ 2017;357:j1608

http://dx.doi.org/10.1136/bmj.j1608 